\title{
Mohamed Chukri y Tennessee Williams nunca se dijeron adiós ${ }^{\mathrm{T}}$
}

\section{Mohamed Chukri and Tennessee Williams never said goodbye}

\author{
Mehdi Mesmoudi \\ Universidad Autónoma de Baja California Sur, México \\ mesmoudipadinha@gmail.com
}

\begin{abstract}
Resumen: Mohamed Chukri (1935-2003) es una figura clave en el género autobiográfico en la literatura mediterránea de las últimas tres décadas del siglo pasado. Su trilogía novelesca lo sitúa como uno de sus grandes representantes en la literatura de lengua árabe. Su obra ha sido traducida al francés, al español y al inglés, lo que ha hecho posible una amplia recepción por la crítica literaria internacional.

En Tennessee Williams en Tánger (2017) se pretende formular la propuesta autobiográfica de Mohamed Chukri con dos objetivos: a) sacar a la luz los diálogos a viva voz de ambos, su concepción de la literatura, su vínculo con la ciudad de Tánger de la fiebre beat; $b$ ) reflexionar en torno a la relación que yace entre una autobiografía y un diario, y los nexos entre la literatura y lo histórico. Estas reflexiones de orden teórico y filosófico -siempre desde las coordenadas chukrianas- se articulan en torno a la escritura misma.
\end{abstract}

\footnotetext{
${ }^{1}$ Este trabajo tiene una enorme deuda con Nordin Mesmoudi, artífice de las entrevistas a Ahmed El Kabachi y Fouad Bouchafa, y con Naima Mesmoudi quien me acompañó al Centre Culturel Boukmakh donde se encuentra una parte del legado de Mohamed Chukri, especialmente el archivo audiovisual. A ambos va dirigida esta mínima mención, sobre todo, mi tío, fiel devoto del Pain $\mathrm{Nu}$.
} 
Palabras clave: Mohamed Chukri, autobiografía, Tennessee Williams, diario, Tánger internacional.

Abstract: In the last thirty of $20^{\text {th }}$ Century, Mohamed Chukri (I9352003) was a key figure in the autobiographical genre oh the Mediterranean literature. His fictional trilogy places him among the best writer in Arabic. His oeuvre has been translated into French, Spanish and English. Thanks to these translations, Chukri has received a considerable amount of attention from literary critics all around the world.

Tennessee Williams in Tangier (2017) leads us to study Chukri's autobiographical writing through a bifrontal axis: a) shed light on the dialogues between the American author and the Moroccan minstrel, their perspectives on literature, and their living experience in a cosmopolitan Tangier; $b$ ) to reflect on the links between the autobiography and diary genres, and the links between literature and historiography. These reflections, from a theoretical and philosophical order -and always from the Chukri's perspectives- are articulated around the act of writing itself.

Keywords: Mohamed Chukri, Autobiography, Tennessee Williams, Diary, International Tangier.

Recibido: I9 de mayo de 2020

Aceptado: 30 de abril de 202 I https://dx.doi.org/I O.I 5 I 74/rv.vi 4i29.549

\section{A modo de introducción}

ada escritura es un inicio, una conversión, un fraudulento
testimonio de fe, una declaración fallida de intenciones, un
retorno imposible (Cassigoli, 2016: 51-56). En cada texto se traza
un peculiar paisaje cuyo escriba nunca pronuncia ese adiós que se 
propuso. Hace más de dos años que inició esta travesía exclusivamente textual - pero también documental y testimonial- en torno a la figura, la vida y la obra de Mohamed Chukri, un escritor marroquí sumamente atípico, reciente en la crítica literaria tanto de lengua árabe como francesa, que nos interpela con interrogantes repletas de ira y hambre, y cuestiona cómo exploramos la literatura y sus turbios vínculos con la vida y el sujeto que la padece. Volver a escribir sobre Chukri sigue siendo un ejercicio difícil, dudoso, doloroso, repleto de duelo. Levantar el lápiz es como cerrar el puño con la tentativa de agredir a la vida o de sellar con esa empuñadura una superficie de madera. Regresar a Chukri es retomar el diálogo que tengo con él, secretamente, y se despliega sin palabras todos los días de mi vida.

Mohamed Chukri es un autor fundamentalmente ligado a la autobiografía, un género narrativo bastante controversial en un mundo árabe e islámico envuelto en el ocultamiento, y en la región mediterránea -que se remonta a Plutarco y San Agustín- inmersa en sus retratos hagiográficos y ejemplarizantes. Este ensayo explora una tipología textual que ha empleado Chukri para abordar su concepción de la autobiografía: el diario. Mediante un recorrido por Tennessee Williams en Tánger se busca indagar en las descripciones del escritor estadunidense durante su segunda visita -brevísima- a Tánger, los lugares que frecuenta, los periódicos y las revistas que lee, los diálogos que entabla con el propio Chukri y otras figuras como Paul Bowles, las bebidas que acostumbra tomar, los modos o las manías que reproduce. Lo anterior es con la finalidad, primero, de extraer una suerte de retrato narrativo y urbano del escritor y sus nexos con una urbe singular- los escritores y los artistas de la época de inicios de los setenta- y, segundo, observar las características formales y discursivas del diario como forma de sumergirnos en la concepción autobiográfica de Chukri. 


\section{Mohamed Chukri y la autobiografía}

Debido a su situación geoestratégica, Marruecos se ha visto envuelto entre inicios y mediados del siglo pasado en múltiples conflictos de carácter mundial, regional y nacional. Por su proximidad geográfica y su afinidad histórico-espiritual se convierte en una sucursal del franquismo allende las aguas mediterráneas, contribuyendo, por un lado, al fomento de la lengua y la cultura árabes y, por otro lado, fortaleciendo involuntariamente las bases del nacionalismo marroquí que se inclinaba por la lengua española como vehículo de comunicación en sus reivindicaciones diplomáticas (Ricci, 2010: 15). Esta singularísima encrucijada histórica hizo del país norafricano uno de los destinos -aunque temporal al iniciode los refugiados que habían sido derrotados en la Guerra Civil: "Con el transcurso de los años, cruzar el Estrecho fue el camino elegido por los españoles que querían una vida mejor, alejados de la miseria que asolaba el país. Marruecos está más cerca que México o que Cuba" (Rojas-Marcos, 2018: 91). Aunado a lo anterior, cabe recordar la participación de Marruecos -debido a su estatuto protectoral francés- al lado de Francia en la Segunda Guerra Mundial. De hecho, mientras Hitler entraba en París, Franco lo hacía en Tánger (52) para preservar los intereses de esta ciudad que, en su momento, gozaba de una condición internacional al margen tanto del protectorado español como francés, manteniendo así su neutralidad político-cultural.

La figura de Mohamed Chukri aparece históricamente en este abanico de coyunturas y su vida se desarrolla de acuerdo a la evolución misma de los conflictos por los cuales atraviesa el país. Chukri es un escritor cuya literatura hunde su hambre y su ira en su propia vida en el contexto que transita del protectorado español en el norte de Marruecos hacia la independencia. Probablemente nos estemos enfrentando a los pocos escritores donde sea difícil se- 
parar su vida de la literatura y ambas de su contexto histórico y sociocultural. Chukri se convierte de esta manera en un "testigo privilegiado" (Del Paso, 2011: 3) de su tiempo sobre los eventos que han marcado el segundo tercio del siglo pasado. De forma más específica, su figura es un asomo histórico-literario por el estatuto internacional de la ciudad de Tánger.

En esta escena de efervescencia político-militar, resurge la ciudad de Tánger - “ciudad mediterránea que mira al Atlántico” (Rojas-Marcos, 2018: 29) - para afianzarse paulatinamente como "una ciudad con una estructura política y social insólita" (51) cuya prensa -inscrita en un orden de "la civilisation du journal" (Kalifa, et al., 2015: 7-21)-, por poner un ejemplo preciso, daba cuenta de una enorme complejidad social (Rojas-Marcos, 2018: 61-75). Debido a esta peculiar condición político-diplomática de Tánger -La ciudad de la mentira (2015) titula Ińaki Martínez una de sus novelas-, en los albores de la posguerra arriba una serie de escritores, pintores y músicos reunidos en torno a una conciencia beat y un síntoma contracultural de época. Me refiero a Paul y Jane Bowles -que iniciaron esta idílica peregrinación por recomendación de Gertrude Stein cuando estaban en París-, a Tennessee Williams, a Truman Capote, a Gore Vidal, a Jack Kerouac, a William Burroughs, a Allen Ginsberg, entre otros, sin obviar a Jean Genet. No olvidemos que Paul y Jane Bowles junto con Tennessee Williams estuvieron en Acapulco, Burroughs había huido de la justicia mexicana por haber asesinado por error a su esposa en una fiesta de amigos, y Kerouac estuvo recorriendo las carreteras del norte de México, sobre todo Tijuana.

A diferencia de aquellos peregrinos urbanos, Chukri veía en Tánger la huida del hambre, la sequía y el abandono de los años cuarenta del Rif en búsqueda insaciable del "paraíso" -como así lo describía su madre- del que encontró solo la libertad del vagabundeo con sus obscuras calles y la delincuencia. Rossana Cassigoli 
declara: "La errancia es a veces una forma de vivir [...]; un camino que conduce a librarse del lastre de la identidad" (2016: 75). Tahar Ben Jelloun, en el prólogo de su versión francesa, afirma: "Mohamed Chukri a tôt connu la violence du besoin, l'exigence de la haine et le visage de la mort" (1980: 7). La ciudad cosmopolita y canalla de Tánger solo le ofrecía como menú un banquete de contrastes que intimidaba a propios y ajenos. Chukri en una entrevista llegó a llamar Tánger "el paraíso de los pobres” ¡ Cuánta verdad descansaba en esa sentencia mientras duraba el ceño fruncido y la mirada perdida en el horizonte mediterráneo! Decrepitud y hambre son dos grandes metáforas que abrevian su autobiografía, incluyendo sus tres diarios Paul Bowles, el recluso de Tánger, Jean Genet en Tánger y Tennessee Williams en Tánger.

En 1973 aparece el primer libro de Mohamed Chukri, la autobiografía titulada For Bread Alone dictada en lengua española a Paul Bowles que traducía en lengua inglesa. Dicha obra se traduce al francés por Tahar Ben Jelloun con el título Le pain nu en 1980. Dos años más tarde aparece la versión en árabe con el título Al-jobz al-hâfî. Esta edición árabe es censurada por las casas editoriales de Marruecos y en el mundo árabe es catalogada como "novela pornográfica” por hurgar en los asuntos más íntimos de la sexualidad, el alcohol, las drogas y otros tabúes de la sociedad marroquí inscrita en sus costumbres islámicas tradicionales. La versión castellana de Abdellah Djbilou titulada El pan desnudo ${ }^{2}$ aparece hasta 1989 y una versión corregida de Rajae Boumediane titulada El pan a secas por Cabaret Voltaire hasta 2012. En otras palabras, la obra que consagró a Chukri a nivel internacional germinaba entre 1973 y 2012. Casi cuatro décadas de creación, recreación y unción involucra a tres escritores de tres lenguas distintas, aunque

${ }^{2}$ El título hace un guiño a otro título El almuerzo desnudo de William Burroughs aparecido en 1959 en la editorial parisina Olympia Press. 
intercomunicados: Mohamed Chukri, Paul Bowles y Tahar Ben Jelloun. Una triada que insiste en la condición colectiva de la literatura y nos recuerda el concepto de "renga" que asumía Octavio Paz (2000: 127).

Con esta novela autobiográfica, Chukri inaugura una literatura testimonial cruda y realista, inscribiéndose en una generación de escritores que se llamaron a sí mismos "los contestatarios" (Chukri, 2017: 20). Una literatura que se enfrenta a los opresores y los caudillos de turno, sin olvidar a los que negociaron secretamente y concesionan sin perdón su libre albedrío. Uno de sus amigos Ahmed El Kabachi, apodado "Rubio" me confesó: "Soy hijo de El pan a secas", afirma que Chukri tuvo su primera máquina de escribir cuando trabajaba de secretario en la Escuela Ibn Battouta de Tánger, murió teniendo entre cuatro mil y cinco mil libros, leía de cinco a nueve de la mañana y luego se dedicaba a vivir, ${ }^{3}$ los autores a quienes leía en sus inicios son de la misma generación literaria, denigrada por la sociedad y los escritores refinados y pulcros. Fouad Bouchafa -quien leyó El pan a secas en lengua francesa- admite que Chukri era un individuo aislado que tenía principios de esquizofrenia, mostraba misericordia con los pobres y los necesitados, amaba la pintura y odiaba el fútbol. A su juicio, la soledad era la preocupación íntima de Chukri, no tenía amigos, solo compańeros de bebida. Tenía miedo de la muerte. La muerte de Berrada, uno de sus amigos más cercanos en la escritura, lo afectó profundamente. ${ }^{4}$

Con la autobiografía, Chukri realiza el primer suicidio literario anteponiendo la honestidad y el pudor textuales antes que los

${ }^{3}$ Entrevista hecha a Ahmed El Kabachi el lunes 7 de enero de 2019 a las 10 de la mañana en su casa, cerca del Café Roxy donde se sentaba el propio Chukri con sus amigos.

${ }^{4}$ Entrevista realizada a Fouad Bouchafa en el Café Zagora de Tánger el martes 8 de enero de 2019, a las 10:30 de la mańana. 
remordimientos del espíritu o el éxito editorial. En cada gesto de escritura, Chukri se acercaba más a ese nirvana, esa violenta sacudida en la obscuridad, una autodestrucción que se renueva en cada resquicio del aire contaminado o la esquina de un burdel. Razón por la cual, Cassigoli recordando a Jean Améry asegura que toda autobiografía es una fragmentación, "una autodemolición" (2016: 133). La autobiografía desde el imaginario literario de Chukri se atreve a sumergirse en la región más incómoda de nuestra intimidad, los vicios y los abusos de nuestra civilización contemporánea. No obstante, lo que revela la propia autobiografía es "la incapacidad de la obra para iluminar determinadas zonas oscuras de la vida interior del poeta” (Darío, 2015: 15) lo que nos conduce a una irremediable extranjería que asciende entre el que escribe y el texto producido, inicialmente, como una referencia a sí mismo. Cassigoli habla de "un sujeto que emerge, se permite decir alguna cosa, en calidad de testigo" (2016: 27). Sobre esta ligadura que mantiene el sujeto testimonial con la obra, Maurice Blanchot ańade al respecto:

Tal vez sea sorprendente que a partir del momento en que la obra se convierte en búsqueda del arte, en literatura, el escritor siente cada vez más la necesidad de conservar una relación consigo. Siente una extrema repugnancia a desprenderse de sí mismo en beneficio de ese poder neutro sin forma y sin destino que está detrás de todo lo que escribe, repugnancia y aprehensión que revela la preocupación, propia de tantos autores, por redactar lo que llaman su Diario (2002: 24).

\section{Flâneries en torno al diario}

Hablar del diario es referirse a la paradoja de su vocablo y la improbabilidad de su determinación. Indica, al mismo tiempo, el curio- 
so síntoma epocal de nuestros tiempos cuando somos testigos de la huida masiva de la escritura hacia el reino de lo virtual. Señala, empero, la inclinación más reciente de los textos que inicialmente poco tienen que ver con lo que difusamente llamamos "literatura". Un diario es el lugar de las confesiones más inusuales, los testimonios más íntimos, las vivencias poco comunes aunque cotidianas, una especie de habitación en un motel de paso o un vagón de tren en plena marcha. Por eso, su condición es instantánea, fragmentaria, refractaria, de migajero constante donde las sanguijuelas y los gusanos hallan, al fin, en un invisible abrazo común, su hormiguero, su diminuta patria, su más ferviente eternidad. Escribir y contar, contar y escribir, escribir contando, contar escribiendo. Operaciones profundamente simultáneas o concatenadas, paralelas o entrecruzadas, que se realizan con el único fin de no olvidar.

Mientras las memorias exploran las facetas públicas de un personaje, la autobiografía se dirige a lo privado. El diario, en cambio, es aún más introspectivo puesto que el que escribe, lo hace inicialmente para sí mismo. Carlos Barral lo define como "texto tan personal y no escrito para la imprenta" (1997: 73). Aunque sucede que hay un riesgo de que dicho diario sea descubierto por alguien más e irrumpa en esa alcoba secreta de las confidencias. Se puede considerar que el diario es un tipo de texto donde el escritor dialoga consigo mismo, "a solas, sin testigo" (Borges, 2009: 158), como diría Fray Luis de León. Por su cercanía a lo cotidiano, el diario está condenado a su proximidad del testigo que vive o dice vivir lo que escribe "a diario", casi a prueba de los días que pasan y pesan sobre el relato: "la verdad del Diario, no [está] en las notas interesantes, literarias, sino en los detalles insignificantes que lo atan a la realidad cotidiana” (Blanchot, 2002: 24). Lo que cabría preguntarse es si ¿el diario es un texto íntimo condenado al anonimato? Si es así, ¿cómo sabemos de la existencia de tantos diarios? ¿Cómo es que existe una producción literaria de corte diarista? 
También, cabría plantear otra interrogante: ¿el diario es ese tipo de texto que en algún momento caerá en manos ajenas? Con estos cuestionamientos señalo la condición fantasmagórica del diario, sus inconsistencias, su arribo repentino. Un diario es el síntoma de los deseos más obscuros, los miedos, su rebeldía, la frustración del que escribe y el tiempo limitado o brevísimo que lo custodia, exponiéndolo, hasta que aparece un nuevo guardián para decidir cómo liberarlo de esa atadura con el anonimato. Este diario "no escrito para la imprenta" debe cruzar la espectrología de su crianza y asumir su nueva condición de bastardía.

Quiero destacar otro rasgo del diario, a diferencia de la autobiografía y la novela autobiográfica, que es su carácter difuso, diminuto y fragmentario. Martín García González apunta a "una narración fragmentaria" (Hugo, 2004: 57), lugar de los destellos, donde el relato es imposible, aunque donde el sujeto "se encuentra" debido a esa naturaleza descompuesta y huidiza de minucias o, para recordar el título de la autobiografía de Rudyard Kipling, Algo de mi mismo; es decir, la ventana o el tímido contraluz de una sociedad y su época. Este texto donde se inscriben "estos apuntamientos" (Darío, 2015: 25) puede ser considerado la especie peregrina y desgraciada de la fauna literaria dedicada a explorar el yo vital debido a que no asume ni pretende reivindicar el grosor de unas memorias o el prestigio de una autobiografía porque "el diario se escribe solo" (Benítez Ariza, 2019), en la penuria y desde la más absoluta decrepitud. Esta condición de orfandad domiciliaria del diario -y que a su vez carga consigo la marca huérfana de su sujeto- que asciende se debe a que el diario como obra "contiene el principio de su ruina" (Blanchot, 2002: 204) y persigue y condena a su héroe que es una víctima. Es por eso que todo texto autobiográfico termina siendo un sacrificio escritural.

Manuel Alberca en El pacto ambiguo (2007) desarrolla y complementa el aporte de Philippe Lejeune cifrado en su El pacto au- 
tobiográfico (1973) donde teoriza en torno a "las novelas del yo" como ese híbrido que se debate entre lo novelesco y lo autobiográfico, lo ficcional y lo testimonial o verídico que deja entrever la relación que la literatura todavía mantiene con lo real de acuerdo a la categoría de "mímesis" de Paul Ricoeur. No vamos a entrar en la discusión que Alberca inicia con Lejeune, sino solamente citar los tres tipos de estas novelas del yo: la autoficción, la autobiografía y la novela autobiográfica. El concepto de "pacto ambiguo", como esa isla que pende entre el pacto novelesco y el pacto autobiográfico, es lo que permite justamente la recepción de estas modalidades novelescas desde una perspectiva ambigua y desconcertante sin que se resuelva. En el primer tipo de novela del yo que es la autoficción, Alberca despliega otros tres fenotipos: la autoficción biográfica, la autoficción fantástica y la autobioficción. Me interesa, más que nada, la autobioficción con la cual Vincent Colonna -discípulo de Gérard Genette que también participa en esta discusión desde su Fiction et diction (2004) - aportó su propia clase de autoficción que es "la autoficción referencial o autobiográfica". Ángel Basanta, en su ensayo "Autoficción e impostura literaria" (2009), comenta precisamente la obra de Alberca e incluye el diario entre las novelas del yo.

El diario -como un modelo de autobioficción- es un desafío puesto que cruza varios géneros literarios. A diferencia de las memorias, la autobiografía y la novela autobiográfica, el diario es el modelo narrativo que está más alejado de la novela puesto que se asemeja a un cuaderno de apuntes, una bitácora de viaje o incluso un dietario. Nos enfrentamos a un texto híbrido que fluctúa entre las arenas movedizas de lo literario y el testimonio verídico y fechado del que vive y registra los respectivos latidos de su más honda intimidad. El Diario de Ana Frank, como ejemplo, es un conjunto de relatos que mantienen un hilo conductor en forma epistolar, todos inician con un "Querida Kitty" y concluyen con un "Tuya, 
Ana”. El otro ejemplo de esta hibridez se puede apreciar en Diario de un poeta recién casado de Juan Ramón Jiménez - descrito por él mismo como "breve guía de amor por tierra, mar y cielo" (97) y "álbum de poeta" (98) - que combina el verso y la prosa; Michael P. Predmore lo define como "autobiografía lírica escrita en forma de diario" (18). Es interesante la condición de incertidumbre y de incompletitud que señala el propio Jiménez al final de su Diario como reflexión teórica en torno al diario y su cotidiano tratamiento, su descuidado cuidado con el tiempo:

Este Diario, más que ninguna otra obra mía, es un libro provisional. Es probable que, más adelante, cuando me olvide de él y lo crea nuevo, lo corrija más, es decir, algo; y es posible que le quite las correcciones que ahora le he hecho y lo deje casi en esencia.

No sé lo que será. Sé que, hoy, me parece este libro mío un boceto de él mismo, no sé si boceto de más o de menos, que me quiero quitar de encima o de debajo, para libertarme (300).

Las mismas inquietudes plenas de extrańeza se pueden leer y apreciar en las palabras de Ana Frank: "He dejado pasar algunos días sin escribir porque quería ante todo reflexionar sobre lo que significa un Diario, no solo porque es la primera vez que tengo uno, sino porque siento que transcurrido un tiempo nadie, ni aun yo, se interesará por las confidencias de una muchacha de trece años" (2000: 10).

Ambos pasajes presuponen elementos constitutivos comunes. El diario es un misterio para el que lo escribe. Se escribe de forma inadvertida y cuando el autor menos se da cuenta. José Manuel Benítez Ariza, reseñando el diario de Andrés Trapiello titulado Diligencias, afirma: "El diario se escribe solo, sí, pero ante testigos; y es obligación del testigo preguntarse por su papel" (2019). El silencio lo fecunda y no las ansias de escribirlo. Es el tiempo y no 
el autor que nutre de savia la escritura. Se debate entre la incompletitud constante y la aspiración modélica de un diario absoluto. La condición migajera en que subsiste acaba corroyendo la materia del diario, la escritura, el relato y el diario mismo. Razón por la cual la actitud que toma el escritor no es solo en relación con la escritura, sino también específicamente con la custodia y el cuidado del manuscrito. El escritor de un diario es también guardián de sus pertenencias. Lo que también nos lleva a pensar el diario como un documento bastante descuidado, deshilachado, desgarrado. Estamos frente a "historias sueltas" (Fernández Lladó, 1993: 20) que reflejan el desafío de unir dichos fragmentos en un documento y la imposibilidad de lo lineal en el relato narrativo: "La obra no es obra si no es la unidad desgarrada, siempre en lucha y nunca apaciguada, y sólo es esta intimidad desgarrada si se ilumina por lo oscuro, floreciendo de lo que permanece cerrado" (Blanchot, 2002: 204). Por esta razón, el mismo Blanchot asegura que en la obra subsiste "un principio de ruina" (204).

A diferencia de la memoria y la autobiografía que son textos escritos a posteriori, el diario es un texto que se produce en el mismo momento de la vivencia aun cuando el autor no comprende lo que acaba de presenciar o lo que está viviendo. Se puede plantear que el diario es un testimonio vivo y fresco del momento, que se narra a viva voz, a un amigo que acaba siendo uno mismo. Martine Bercot lo define de esta manera: "Catégorie particulière du genre autobiographique, le journal [...] s'impose comme un témoignage direct du vrai" (Maupassant, 1994: 7-8). Debido a esa condición inédita del testimonio y la falta de secuencia narrativa, nos empuja a enfrentarnos a puros destellos, zarpazos del momento o instantes brevísimos de quietud en la batalla como en el Diario del Che en Bolivia. En esta contienda autobiográfica se inscribe el diario Tennessee Williams en Tánger de Mohamed Chukri. 
El diario - desde las dimensiones teóricas y filosóficas de Chukriestaría conectado con la historia de las migajas de François Dosse, la microhistoria de Maurice Aguillon, una suerte de etnografía de los sucesos pequeños y las historias mínimas. Un diario ${ }^{5}$ donde su protagonista sería un autor bastante peculiar: "Yo no soy un historiador. Pero soy un testigo de mis tiempos. Un testigo privilegiado" (Del Paso, 2011:3), unos tiempos marcados por la conciencia beat de los escritores y artistas que arribaron a la ciudad de Tánger a dejar a su vez sus testimonios y a entrelazarlos con las voces y las vicisitudes de los autores locales. Chukri se erige como un "ser de correspondencias, un lugar de encuentros" (Paz, 2014: 977), un vínculo entre escritores y artistas de su tiempo allende las fronteras.

En vez de hablar propiamente de una autobiografía, el diario señala la dimensión de lo autobiográfico concebido como todo aquello que irrumpe repentinamente, inapropiadamente y expropiadamente de su condición domiciliaria; aquello que carece de estructura, solo secuencias interrumpidas, desgarradas internamente, con un delgado hilo que las arrastra; un rincón de la casa invadiendo todas las partes lo que nos lleva al concepto de "la basura" en Žižek como discurso radical sobre la migración y los desplazamientos continuos; la noción del doble o el fantasma en Nerval, Lamartine, Maupassant y Rimbaud; el diario como el

${ }^{5}$ En el tercer relato fechado del 18 de julio de 1973, sentado junto a Yacoubi y Tennessee Williams en el Café de Paris, menciona un dietario (2017: 42) aunque sin referencia al diario que iba a escribir sobre el escritor estadunidense. ¿A qué se refería Chukri con su dietario? ¿Es el incipiente diario que iba a escribir sobre el escritor o era un cuaderno de anotaciones? Estas preguntas apuntan a la condición de Chukri obsesivamente reflexiva en torno a los aspectos vinculados con la literatura. Al tratarse de una traducción, resulta conveniente acudir a la versión en árabe y observar si Chukri emplea un vocablo distinto al del diario o si es el mismo. Lo que sí importa aquí es que Chukri tenía ciertas inquietudes filosóficas y teóricas sobre textos con cierta inclinación a lo autobiográfico y a la literatura intimista. 
lugar donde se hace visible y se realiza la imposibilidad de una autobiografía.

\section{Mohamed Chukri y Tennessee Williams en Tánger}

Si la literatura en los Estados Unidos -a juicio de Paz (2014: 559) - empieza con Walt Whitman y Edgar Allan Poe y en Francia -a juicio de Foucault (2013: 86-87) - con el Marqués de Sade; en Marruecos, se podría hacer la analogía con Mohamed Chukri. La literatura inicia su sendero en el instante preciso de la transgresión y cuando un escritor rompe con la tradición de sus predecesores (84-90). Solo desde las coordenadas de "la tradición de la ruptura", según Paz, se inaugura la modernidad literaria. En este escenario transgresor en el discurso literario se inscribe la figura de Chukri. Aunado a lo anterior, hay que señalar las alucinaciones y la conciencia decadente que atraviesa a los escritores y se devela a la hora en que escriben. Los fantasmas de Chukri revelan una audacia aventurera, un espíritu visionario y una honestidad escritural sin titubeos. Cabe recordar que Albert Béguin señalaba a Nerval como el primer poeta moderno con tendencia al tedio antes que Baudelaire (2014), Verlaine o Rimbaud. Chukri justamente transita en esta cáfila de decadentistas resignados a la derrota y que nunca vieron salvación en su propia escritura.

Mohamed Chukri es uno de los grandes autores de la autobiografía que ha iniciado un interesante debate, aunque incómodo sobre la literatura intimista o de la experiencia que retrata con crudeza el inframundo urbano de posguerra donde vagabundean los nińos de la calle con su infancia durante la contracultura. No es fortuito que Orhan Pamuk -en uno de los títulos de su obra- haya concebido la infancia como "museo de la inocencia", algo lejano y ajeno para el escritor marroquí que se puede apreciar desde su escritura. Además de la trilogía autobiográfica -El pan a secas, Tiem- 
po de errores y Rostros, amores, maldiciones-, escribió tres diarios. El primero se titula Paul Bowles, el recluso de Tánger, el segundo Jean Genet en Tánger y el tercero Tennessee Williams en Tánger. En los seis textos aparece Tánger trazando el rostro de su difusa topografía narrativa.

¿Puede un relato de dos semanas de encuentros, conversaciones, caminatas e impresiones constituir un diario? ¿A qué tipología de diario nos estamos enfrentando? ¿Es un diario autobiográfico o, más bien, combina lo propio y lo ajeno? ¿Es posible un diario que conjuga la autobiografía y a la vez una diminuta biografía de otro escritor? Aunque Lambert lo define como "librito", Chukri se refiere a este librito como "diario" en cuatro ocasiones (81, 84, $89,108)$ y emplea la palabra "diario" para referirse al libro que antes también había escrito sobre Genet (27). Chukri lo describe como "relato de nuestros encuentros" (113). Un diario concebido como una bitácora de anotaciones narrativas, un cuaderno de impresiones y anécdotas de diálogos con el escritor estadunidense y el círculo intelectual y cultural que giraba en torno a él, su obra y de Tánger como urbe domadora de sedientos talentos.

El "librito" consta de 120 páginas y se puede leer con facilidad en una tarde de verano. Está constituido de un prólogo de Gavin Lambert. El diario va del 16 de julio al 9 de agosto de 1973, lo componen trece relatos de distinta extensión y un curioso epílogo del propio Tennessee Williams. La inclusión de la voz de Williams en este diario, aunque al final, apunta a ese juego transversal entre lo autobiográfico y la biografía. En las páginas 82 y 83 aparecen dos fotografías, la primera donde está Chukri, Williams y una turista estadunidense en el Bar Parade que data del mes de agosto de 1973. Se observa una botella de vino, dos copas servidas, un plato y unos lentes. Chukri y la turista están sentados, Williams está de pie con las manos en los hombros de ambos. En la segunda foto de la misma velada, además de los tres referidos anteriormente se en- 
cuentra otra turista estadunidense. En el texto a pie de foto señala que ambas fotos "pertenecieron a Mohamed Chukri" (83). En la cubierta aparece una fotografía de Tennessee Williams datada de 1953 -que se encuentra en el Vandamm Studio- y en la guarda una fotografía de Chukri sin fecha tomada por Rachid Ouattassi, uno de sus fotógrafos y grandes amigos.

Antes de explorar este diario hay que señalar que de los 63 títulos publicados hasta 2017 en la editorial barcelonesa Cabaret Voltaire, nueve son de autores marroquíes - uno de cada siete títulos corresponde a un autor marroquí- de los cuales siete son de Mohamed Chukri dedicados a su trilogía novelesca, los dos diarios dedicados a Bowles y Genet, y dos colecciones de cuentos El loco de las rosas y Zoco Chico. Estamos ante la casa editorial fuera de Marruecos que más atención le ha dedicado a Chukri, ingresándolo en el imaginario literario y sociocultural de lengua espańola con la participación y colaboración de ilustres traductoras marroquíes como Malika Embarek López, Karima Hajjaj y Rajae Boumediane El Metni. La labor de la traducción hace posible que un escritor sea leído por usuarios a los que inicialmente no estaba predestinado el libro; sin embargo, su obra -desde los postulados arqueológicos de Foucault (2015: 32-41) - transgrede el lugar originario de producción del texto y atraviesa su geocultura literaria, proyectándose allende los filtros aduanales de la lengua custodiadora. Por esta razón, Chukri no es un autor de una lengua precisa, sino un escritor entre literaturas.

El prólogo de Gavin Lambert -escritor y biógrafo británico, amigo de Bowles- es de una honda frescura y ofrece otras latitudes, circunstancias y efectos del diario de Chukri. No solo nos introduce en la atmósfera íntima tanto de Chukri como de Tennessee Williams, sino también explora los retratos psicosociales de ambos a través de sus literaturas y su recepción. Es un brevísimo ensayo que combina el estilo sencillo y pulcro sin abandonar la apuesta 
estética y el extraordinario compromiso por registrar un acontecimiento peculiar en la literatura de nuestros tiempos marcados por la globalización, la interconexión cultural y la versatilidad identitaria. El prólogo es un apéndice que explora, expande y exprime el texto de Chukri. Lo explora en la medida en que lo interroga y lo interpela. Lo expande en cuanto a su efecto a posteriori de agregar datos, impresiones y precisiones en una dimensión contextual del encuentro entre dos escritores en un ambiente literario y cultural privilegiado. Lo exprime de tal manera que lo reduce a migajas, lo vuelve líquido, pugna mudamente con él, inadvertidamente, y es aquí donde el prólogo adquiere visibilidad y aspira a cierta autonomía y disidencia. El prólogo de Lambert, contagiado por la fiebre epocal de sus feligreses, está apropiándose de esas características contraculturales del espíritu beat entre mediados de los 50 y principios de los 70.

Lambert se refiere al diario como "librito [...] [que] describe una serie de encuentros, la mayoría de ellos fortuitos" (2017: 11) mediados por el azar. Gracias a este prólogo, podemos apreciar que no solo Chukri observaba a Tennessee Williams, sino también viceversa: "(Cuando me bajé del coche en el Boulevard Pasteur, principal arteria del barrio moderno de Tánger, vi a lo lejos a Chukri, era delgado, rasgos afilados, iba solo, camino de un café, con un montón de libros y cuadernos bajo el brazo)" (13). Este pasaje nos muestra que el escritor estadunidense también gustaba (quizá) de anotar sus impresiones acerca de los encuentros con escritores, lo que nos lleva a suponer que tal vez custodiaba esas "historias sueltas”, ¿qué esconden esos relatos, esos “apuntamientos” como los llama Rubén Darío? (2015: 25) ¿Cómo describiría al escritor marroquí? Sería estimulante para la crítica literaria aventurarse a imaginar ese hipotético diario de Tennessee Williams sobre Mohamed Chukri. Tal vez eso nunca haya pasado, pero nada nos impide creerlo (Borges, 2009: 60). 
El diario inicia de una forma peculiar: "Estaba en casa de Paul Bowles. - Tennessee Williams estará el domingo aquí- me dijo en español.- Por fin vuelve" (19) lo que nos sugiere que es la continuación de un texto anterior, la reanudación de una conversación pasada. También es un guiño al inicio del diario Jean Genet en Tánger: "Estaba sentado en el Café Central con Gerard Beatty. — iMira! - me dijo de repente-. Aquél es Jean Genet" (2013: 13). Este recurso literario aparece, también, en Tiempo de errores con un repentino diálogo (2013: 25) que alude a la continuación de El pan a secas y las malandanzas del joven Chukri. Son llamativos los inicios de ciertos textos de Chukri como El pan a secas que comienza con un fragmento radiofónico:" "Buenos días, madrugadores. Buenos días, trasnochadores. Buenos días Tánger atrapada en una época mercurial" (2014: 11) o la interconexión de ciertos textos a los que me refería antes, lo que muestra una intensa correspondencia entre los libros de Chukri; es decir, tal vez nos enfrentemos a una literatura profundamente autorreferencial e intertextual. Un rasgo que no solo caracteriza la obra de Chukri, sino que subraya su lugar trascendental en la literatura beat y su "escritura palimpsestual".

El diario transcurre -insisto- durante la repentina estancia veraniega de Tennessee Williams en Tánger del 16 de julio al 9 de agosto de 1973.7 Su trama se despliega en los cafés y los bares, en las calles del Boulevard Pasteur, en la casa de Paul Bowles y en

${ }^{6}$ Mohamed Chukri tenía varios programas de radio donde iba a compartir con los radioescuchas sus inquietudes sobre la actualidad literaria, lo que pensaba de los escritores y sus traumas autobiográficos.

${ }^{7}$ La primera visita de Tennessee Williams a Tánger data de inicios de los sesenta. Probablemente entre 1962 y 1964 de acuerdo con la afirmación de Chukri en el cuarto relato del diario (73) cuando comenta que Larbi Layachi -autor de Una vida llena de agujeros grabada en árabe dialectal y transcrita en lengua inglesa por Paul Bowles en 1960- era cocinero del escritor estadunidense en 1962. 
la oficina de Correos donde se registran las curiosas pertenencias del escritor estadunidense en medio de un ambiente hostil y de incomprensión. El diario inicia en la casa de Bowles y de repente se escucha la noticia de que Tennessee Williams regresa a Tánger después de casi una década (19). El escritor marroquí Mohamed Zafzaf -que forma parte de la misma generación de "los contestatarios” que Chukri- describe así a Tennessee Williams cuando lo vio en el estudio del pintor marroquí, Mohamed Yacoubi: “- $\mathrm{Pa}$ rece que no se fía de los extraños [...]. Sólo se muestra afectuoso con los conocidos. Iba bien vestido, impecable, con un bonito traje. Nada que ver con esos escritores que no cuidan su aspecto. $\mathrm{Su}$ amigo llevaba una buena cámara de fotos. Tennessee parecía contento. Se reía de todo lo que decía o hacía Yacoubi” (21). Es el propio Zafzaf el que le sugirió la idea de escribir un diario sobre Tennessee: "- Intenta hacerte amigo de Tennessee Williams [...]. Así podrás escribir un libro sobre él, como hiciste con Jean Genet" (23).

El diario de Chukri es un vagabundeo constante en torno a los lugares más representativos del círculo literario que giraba en torno a Paul Bowles y la Librairie des Colonnes. Recordemos que ambos universos representaban una atracción para los viajeros que venían a visitar y explorar el misterio de Tánger. Es conveniente señalar el Café de París como el lugar idóneo de casi todos los encuentros de Tennessee Williams con Mohamed Yacoubi, Baxter y Chukri. Los cafés son cruciales en nuestra tradición literaria mediterránea de la cual la rioplatense, por ejemplo, no es ajena como nos lo mencionan Santiago de Luca (2018: 5-8) y Alejandro Dolina (20-32). Williams estuvo hospedado en el Hotel Minzah, el mismo donde se había alojado Jean Genet durante su estancia en Tánger. En el tercer relato tanto Yacoubi como Chukri se encuentran a Williams en la calle saliendo de una tienda cerca del Minzah (40) y vuelven a dirigirse al Café de Paris hasta que el sol se oculta 
detrás del consulado francés para ir al salón de té Madame Porte donde iba Williams con Jane Bowles en su primera visita a Tánger (43). Este lugar es descrito por Yacoubi como "el mejor salón de té de Tánger" (44) y donde Williams reconoce que a Jane "le gustaba mucho venir" (44) es donde el escritor quedaría inmortalizado: "Paul Bowles me contó un día, en 1961, vino con Tennessee aquí, a Madame Porte, con algunos amigos. Borracho como una cuba, Tennessee se cayó de espaldas. [...]. Lo dejaron tirado boca arriba en el suelo hasta que pudo levantarse por sí mismo. Tennessee estalló en carcajadas, pero su amigo Frank Merlo estaba muy enfadado" (46).

Los lugares que frecuenta Tennessee con Chukri son en su mayoría los cafés, los bares, los salones de té y las casas de los escritores. Dichos espacios dan cuenta de un círculo literario ${ }^{8}$ bastante cerrado y elitista que nos recuerda a los integrantes de la Escuela de Barcelona de los Gil de Biedma y Carlos Barral. Son lugares que funcionan como un contraluz desde el cual se observa una sociedad y se extraen fotografías mentales, paisajes antropológicos aunque con un toque urbano donde se perpetúa y se inmortaliza su gente, sus hábitos, sus gestos, sus vestuarios... Son lugares abiertos y bulliciosos que dan la impresión de mezclarse con la gente mas no de fundirse en ella, sino de mantenerse al margen. Por esta razón, Chukri se convierte en un "testigo privilegiado" y

${ }^{8}$ Entre los individuos que son citados en este libro podemos nombrar a Timothy Leary (1920-1996), escritor estadunidense, activista a favor del uso terapéutico de las drogas psicodélicas (39); Francis Bacon, pintor irlandés que vivió una temporada en Tánger (51); Kristians Tony, pintor surrealista holandés que vivió en París y Paul -Bowles le ayudó a vender sus cuadros (65)-; los Gerofi dueńos de la Librairie des Colonnes, dependiente de la editorial Gallimard (85); John Hopkins, escritor estadunidense (1938), en Tánger frecuentó a Bowles y Burroughs y escribió sus Diarios de Tánger 1962-1979 (88); Brion Gysin (19161986), escritor y pintor inglés aunque de ascendencia canadiense, tenía un restaurante en Tánger llamado Las mil y una noches (105). 
valiosísimo de esas tertulias del Tánger internacional al margen de la Europa de posguerra.

Lo interesante de este diario es la variada extensión de los relatos que lo componen. Por ejemplo, el cuarto relato es el más extenso, consta de 23 cuartillas y el quinto es de apenas tres oraciones: "Me encontré con Tennessee y su amigo Baxter en la avenida Mohamed V. Parecía molesto. Su sonrisa reflejaba cansancio" (80). En dicho diario, Chukri muestra su conocimiento y familiaridad con su obra La gata sobre el tejado de zinc caliente -traducida a la lengua árabe como Una gata sobre el fuego-, Dulce pájaro de juventud, De repente el último verano, El zoo de cristal (44) y Orfeo desciende (56). Todas ellas traducidas por Mohamed Samir Abdelhamid (57). Gavin Lambert en el prólogo señala: “¿Quién sabe? Tal vez nos volvamos a ver un día de estos', le dice Tennessee antes de marcharse. (Por desgracia, nunca se volvieron a ver)" (15). El encuentro que tuvieron refleja una profunda reciprocidad y unas correspondencias literarias, vitales y filosóficas que difícilmente pueden ser descifradas en este artículo.

Este diario no solo es el retrato y el testimonio de dos escritores unidos por la curiosidad, la admiración y la inquietud por la escritura nocturbana, sino también es un asomo por otras figuras que aparecen, aunque equidistantemente, por los episodios de Chukri. Aunque no les presta la misma atención que a Tennessee Williams, no pasan desapercibidos lo que demuestra que han sido bien tratados puesto que simbolizan la arquitectura literaria y artística de una ciudad atípica. Este diario es un extraordinario caleidoscopio de biografías diminutas que es la metáfora de las migajas literarias que recorren la escritura chukriana. 


\section{Segundas conclusiones preliminares}

En este artículo he planteado revisar los presupuestos teóricos y filosóficos de la autobiografía cifrados en la tipología textual del diario en Mohamed Chukri concebido como un espacio peculiar de encuentro entre dos "seres de correspondencia" (Paz, 2014: 977) donde la autobiografía de uno y la biografía de otro se miran el rostro en una operación huidiza. Esta concepción refractaria de Chukri hacia el diario reconfigura conceptual y teóricamente el trabajo autobiográfico, orientado hacia su inconclusión, hacia su imposibilidad de ser.

Me atrevo a plantear ciertas preguntas como antesala de otro trabajo posterior: ¿acaso no podríamos imaginar ese posible reencuentro al que se refiere Lambert en el "Prólogo" (Chukri, 2017: 15)? ¿La crítica no debería dejar un poco de lado los datos duros y los aspectos empíricos y explorar las regiones azarosas de la incertidumbre? Este texto pretende iniciar con esta curiosa e impertinente aventura donde vislumbremos esa empresa harto compleja porque lo que tiene este diario, en comparación con los demás, es que está marcado a tal grado por el otro que no podemos imaginar a Chukri sin Tennessee y viceversa. Y justo aquí radica el éxito del escritor marroquí y la singularidad de su diario.

\section{Referencias}

Alberca, Manuel, 2009, El pacto ambiguo. De la novela autobiográfica a la autoficción, Justo Navarro (pról.), Biblioteca Nueva, Madrid.

Barral, Carlos, 1997, Diario de "Metropolitano", Luis García Montero (ed.), Cátedra, Letras hispánicas, Madrid. 
Basanta, Ángel, 2009, "Autoficción e impostura literaria”, Revista de Libros, Nueva Época, núm. 147, marzo. Disponible en: https://www.revistadelibros.com/articulos/el-pacto-ambiguode-manuel-alberca-entre-autobiografia-y-novela

Béguin, Albert, 2014, Gérard de Nerval, Juan Almela (trad.), Fondo de Cultura Económica, México.

Benítez Ariza, José Manuel, 2019, "Los diarios se escriben solos", Letras Libres, 12 de agosto. Disponible en: https://www.letraslibres.com/espana-mexico/literatura/los-diarios-se-escribensolos-0

Blanchot, Maurice, 2002, El espacio literario, Vicky Palant y Jorge Jinkis (trads.), Editora Nacional, Madrid.

Borges, Jorge Luis, 2009, Siete Noches, Roy Bartholomew (epílogo), Fondo de Cultura Económica, México.

Cassigoli, Rossana, 2016, El exilio como sintoma. Literatura y Fuentes, Universidad Nacional Autónoma de México/Metales pesados, México/Santiago de Chile.

Choukri, Mohamed, 1980, Le pain nu, Tahar Ben Jelloun (trad.), Librairie François Maspero, La Découverte, París.

, 2013, Tiempo de errores, Karima Hajjaj y Malika Embarek López (trads.), Mohamed Berrada (pról.), Cabaret Voltaire, Barcelona.

Mohamed, 2014, El pan a secas, Rajae Boumediane El Metni (trad.), Cabaret Voltaire, Barcelona.

Mohamed, 2014, Rostros, amores, maldiciones, Housein Bouzalmate y Malika Embarek López (trads.), Cabaret Voltaire, Barcelona.

Mohamed, 2017, Tennessee Williams en Tánger, Rajae Boumediane El Metni (trad.), Gavin Lambert (pról.), Tennessee Williams (epílogo), Cabaret Voltaire, Barcelona. 
Mohamed, 2017, Al-Jobz al-hâfî (versión en árabe), AlFanak, Debolsillo, Casablanca.

Darío, Rubén, 2015, La vida de Rubén Dario escrita por él mismo, Francisco Fuster (ed., intro., y notas), Fondo de Cultura Económica, México.

Del Paso, Fernando, 2011, Bajo la sombra de la Historia. Ensayos sobre el islam y el judaísmo, vol. 1, Fondo de Cultura Económica, México.

De Luca, Santiago, 2018, "La lágrima en el cafe”", Sures. Las voces de los cafés, invierno, pp. 5-8.

Dolina, Alejandro, 2018, "La Indiferencia de las mesas", Sures. Las voces de los cafés, invierno, pp. 20-32.

Foucault, Michel, 2015, ¿Qué es un autor?, apostillas a ¿Qué es un autor? de Daniel Link, Silvio Mattoni (trad.), El cuenco de Plata, México.

, 2013, La grande étrangère. À propos de la littérature, Philippe Artières, Jean-François Bert, Mathieu Potte-Bonneville y Judith Revel (ed., y presentación), École Haute des Études de Sciences Sociales, París.

Frank, Ana, 2000, Diario de Ana Frank, Carmen H. de Grossi (pról.), Mexicanos Unidos, México.

Fuentes, Alfonso y Emilio Sanz de Soto, 2013, Los Fuentes de Tánger, Khbar Bladna, Tánger.

Guevara, Ernesto, 1996, El diario del Che en Bolivia, Fidel Castro (intro.), XxI, El hombre y sus obras, México.

Gusdorf, Georges, 1991, "Condiciones y límites de la autobiografía", Anthropos. Boletin de información y documentación, vol. 9, núm. 125, pp. 9-18. Disponible en: https://dialnet. unirioja.es/servlet/articulo? codigo $=282704$

Hugo, Victor, 2004, El último día de un condenado a muerte. Claude Gueux, Martín García González (ed., y trad.), Akal, Madrid. 
Jiménez, Juan Ramón, 2001, Diario de un poeta reciencasado, Michael P. Predmore (ed.), Cátedra, Letras Hispánicas, Madrid.

Kalifa, Dominique, et. al. (dirs.), 2011, La civilisation du journal. Histoire culturelle et littéraire de la presse française au XIX ${ }^{\mathrm{e}}$ siècle, Nouveau Monde, París.

Klein Bosquet, Oliver, 2016, "El exilio español en el Magreb”, en Exilios en el mundo contemporáneo: vida y destino, Universidad Rovira Virgili/Universidad Autónoma de Ciudad de México, Tarragona/México, pp. 201-224.

Labrador Méndez, Germán, 2017, Culpables por la literatura. Imaginación política y contracultura en la transición española (19681986), Akal, Madrid.

Lejeune, Philippe, 1993, "Le pacte autobiographique", Poétique. Seuil, núm. 14, pp. 137-162.

Maupassant, Guy de, 1994, Le Horla. Première et deuxième version suivi de Lettre d'un fou, Martin Bercot (presentación y notas), Le livre de Poche, Les Classiques d'aujourd'hui, París.

Nerval, Gerard de, 2014, Aurélia \& Las quimeras, Tomás Segovia (trad.), Conaculta, Clásicos para hoy, México.

Paz, Octavio, 2014, Obras Completas, vol. 2, Excursiones e incursiones. Dominio Extranjero. Fundación y disidencia. Dominio Hispánico, Fondo de Cultura Económica, México.

Paz, Octavio y Julián Ríos, 2000, Solo a dos voces, Fondo de Cultura Económica, Tierra Firme, México.

Ricci, Cristián H., 2010, Literatura periférica en castellano y catalán: el caso marroqui, Orto/Universidad de Minnesota, Madrid.

Rodríguez, Francisco, 2000, "El género autobiográfico y la construcción del sujeto autorreferencial”, Filología y Lingüistica, vol. 2, núm. xxvi, pp. 9-24. Disponible en: http://www.kerwa. ucr.ac.cr/bitstream/handle/10669/14169/4514-6810-1-рв. pdf?sequence $=1$ \&isAllowed $=y$ 
Rojas-Marcos, Rocío, 2018, Tánger, segunda patria. Una ciudad imprescindible en la historia y la literatura española, Almuzara, Madrid.

Sartre, Jean Paul, 2016, ¿Qu’est ce que la littérature?, Arlette ElkaïmSartre (Prefacio), Gallimard, París.

Silva Carreras, Alejandra, 2016, "Literatura del yo: reflexiones teóricas perspectivas de autor en el género autobiográfico", $K a ́$ ñina. Revista de Artes y Letras, vol. 2, núm. xL, pp. 149-158. Disponible en: https://www.scielo.sa.cr/pdf/kan/v40n2/22152636-kan-40-02-00149.pdf 